\title{
Control of responding by a conditioned reinforcer in the presence of free food*
}

\author{
L. A. ALFERINK, E. K. CROSSMAN, and C. D. CHENEY \\ Utah State University, Logan, Utah 84322
}

\begin{abstract}
It has been reported that animals will "work" in preference to "freeloading." However, the variables responsible for this phenomenon are not well understood. Two pigeons were trained to keypeck for food on a fixed-ratio 300 schedule. Next, the food hopper was propped up to permit continuous access to food, and the presence or absence of the hopper light was manipulated. When the hopper light was presented contingent upon the fixed-ratio schedule, keypecking occurred; when it was not presented, keypecking ceased. Thus, responding in the presence of free food was shown to be a function of the conditioned reinforcing properties of the hopper light.
\end{abstract}

Several studies have reported that animals prefer working for reinforcers rather than "freeloading." For example, Stolz and Lott (1964) have shown that rats will run over a pile of food pellets in a runway in order to reach a goalbox containing a single pellet. Jensen (1963) reported that rats would barpress for food when a cup containing food was present in the chamber. Neuringer $(1969,1970)$ has shown that pigeons will learn to keypeck for a food reinforcer in the presence of freely available food and may average up to 40 responses per reinforcer on a variable-interval schedule.

The explanations offered to account for this phenomenon are that the responses investigated are prepotent since they are food-getting operants (Neuringer, 1969) or that these operants have "intrinsic appeal" (Jensen, 1963). However, stating that barpressing has "intrinsic appeal" does not explain the barpressing, but simply changes what we need to explain from the barpressing to its "intrinsic appeal." The purpose of the present study was to manipulate a variable which could affect responding in the presence of free food: the presence or absence of a hopper light.

\section{METHOD}

\section{Subjects}

Two experimentally naive mixed-breed pigeons (P 285 and $P$ 157) served as experimental $S$ s and were maintained at approximately $80 \%$ of their ad lib weights during training. During the course of the study, while food was freely available in the experimental chamber, sessions were conducted $3 \mathrm{~h}$ a day, 6 days a week. Thus, at the beginning of every session, each $S$ was $21 \mathrm{~h}$ food-deprived. Water was available at all times in the home cage.

*This research was supported by NASA Grant NGR 45-002-022 to E. K. Crossman, principal investigator. Reprints may be obtained from Larry $A$. Alferink, Department of Psychology, Utah State University, Logan, Utah 84322. Portions of this paper were presented at the Rocky Mountain Psychological Association Convention, May 1972.

\section{Apparatus}

Sessions were conducted in a typical three-key operant conditioning pigeon chamber (Lehigh Valley Electronics). The left key was transilluminated with red light. The reinforcer was access to Purina Pigeon Chow, a commercial pigeon food of uniform consistency, which was delivered by an electromechanical food hopper. This hopper could be raised and lighted. Hopper access was a $6.5 \times 4 \mathrm{~cm}$ opening located $10 \mathrm{~cm}$ below the key. A houselight and white masking noise were on continuously. The experiment was controlled and data recorded by electromechanical equipment housed in an adjacent room.

\section{Procedure}

Both $\mathrm{S} s$ were trained to peck the red key on a gradually increasing fixed-ratio schedule of reinforcement until FR 300 was attained. At the completion of 300 pecks, the key went dark, the hopper light came on, and the hopper was raised for $3 \mathrm{sec}$. When keypecking was consistent and stable, the food hopper was physically propped in the up position. Thus, an S had continuous free access to food for the remainder of the experiment. Six sessions were then conducted on the FR 300 schedule in which the key was darkened and the hopper light was turned on for $3 \mathrm{sec}$ following each ratio. In the subsequent condition lasting six sessions, the hopper light was no longer presented after 300 pecks, but the hopper remained propped up. In the last condition, still with the hopper continuously up, the 3-sec hopper light was again presented after the completion of each FR 300.

\section{RESULTS}

Responding on the FR 300 was developed and maintained at a high rate. The pattern of responding was typical of that obtained in FR schedules (Ferster \& Skinner, 1957). However, when the food hopper was propped in the up position with the FR 300 in effect, responding on the key decreased for both Ss.

Examination of the cumulative records shows that the presentation of the hopper light contingent upon 300 responses was followed by a long pause and, subsequently, by a high and consistent rate of responding. This is the typical break-and-run pattern developed by fixed-ratio schedules. Accordingly, it closely resembled the pattern during training, when the 


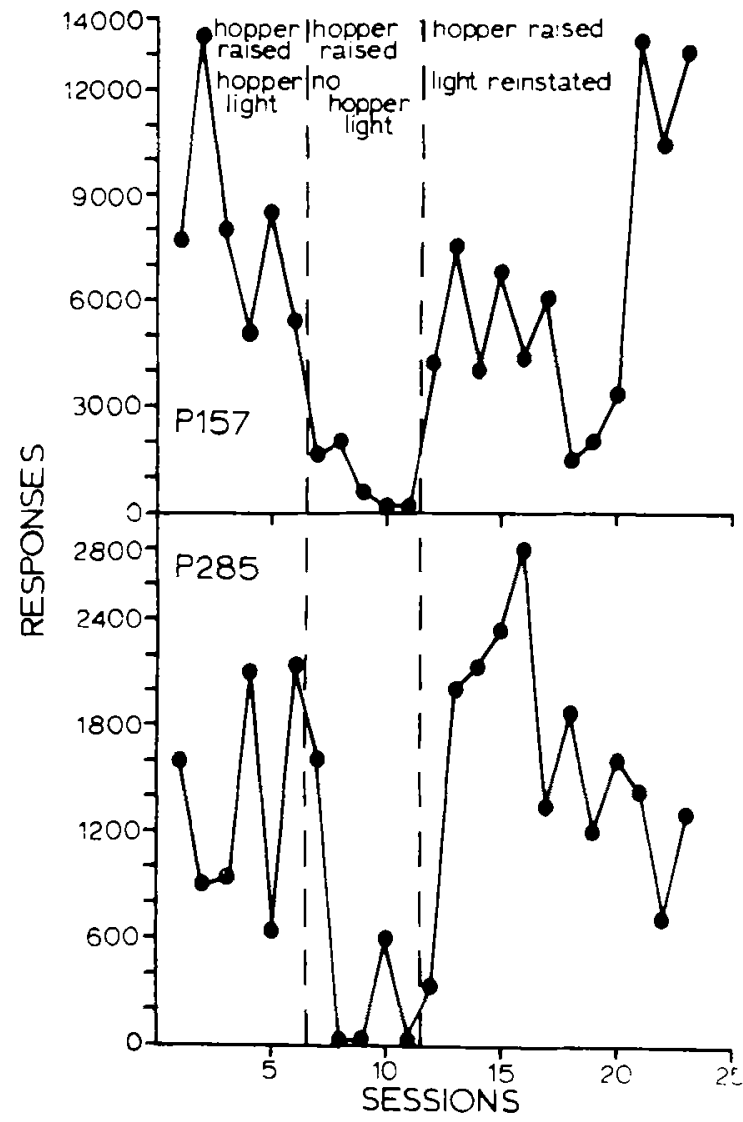

Fig. 1. The number of responses in each session for $P 157$ and $P$ 285. The food hopper was raised at all times, permitting free access to food. The 3 -sec hopper light was presented following every 300 responses in the first and third panel, but was not presented in the middle panel. Note the difference in the ordinate scale for each $\mathrm{S}$.

only food available was presented contingent upon FR 300 responding. Visual observation of the birds revealed that they frequently ate during the postreinforcement pause when the hopper light was off.

Both Ss continued to emit a large number of responses in the presence of free food as shown in the first panel of Fig. 1. When the hopper light was no longer presented, and the hopper remained up, both $\mathrm{S}$ s stopped responding altogether, as is indicated in the middle panel in Fig. 1. Since neither $\mathrm{S}$ responded in this condition, keypecking had to be reshaped using the hopper light alone as a reinforcer for approximations. Responding quickly recovered as shown in the third panel of Fig. 1.

\section{DISCUSSION}

The present study indicates that keypecking in the presence of free food can be controlled by the presentation or removal of the hopper light. When the hopper light was contingent upon completion of the fixed ratio, responding occurred; when the hopper light was withheld, responding ceased. When the hopper light was agam presented contingent upon responding. keypecking rapidly recovered. Since the Ss ate whether the hopper light was on or off, it is clear that keypecking was not maintained by food alone. The fact that responding was maintained only when responses produced the hopper light suggests that the hopper light was a potent conditioned reinforcer.

Conditioned reinforcers are stimuli which acquire their ability to maintain responding through being paired with an unconditioned reinforcer, such as food. Since the hopper light had been paired with food, it became a conditioned reinforcer. In fact, hopper lights are commonly used in studies illustrating conditioned reinforcement effects (see Hendry, 1969). Such conditioned reinforcers can control a large number of responses under conditions in which responses are never reinforced with food (Zimmerman \& Hanford, 1967: Thomas \& Hanson, 1970) or when those responses actually decrease the frequency of food delivery (Thomas, 1969). In view of such findings, it is not surprising that in the present study hopper light presentation maintained and reestablished responding in the presence of free food.

The principle of conditioned reinforcement can also be used to explain the results of some previous studies. When Neuringer (1969) placed a Plexiglas cover over the food hopper, the conditioned reinforcers were no longer paired with food and the behavior was not sustained. The behavior could be maintained only when the animal was allowed access to the food, which permitted the pairing of a number of stimuli with the food. In the Stolz and Lott (1964) study, the rat received not only the single pellet in the goalbox, but also stimuli which had been repeatedly paired with the food pellet and had therefore acquired conditioned reinforcing properties.

The present study demonstrated a variable which controlled keypecking and which provides an explanation of responding in the presence of free food. This conditioned reinforcement explanation makes the at tempt to draw analogies between the preference for the "work over freeloading" phenomenon and the human welfare system somewhat less plausible (Singh, 1972). The fact that people still work in the presence of the welfare system is perhaps due to their "values," which Skinner (1971) suggests are the conditioned reinforcers of a culture.

\section{REFERENCES}

Ferster, C. B.. \& Skinner, B. F. Schedules of reinforcement. New York: Applet on-Century-Crofts. 1957.

Hendry, D. P. Conditioned reinforcement. Homewood, III: Dorsey Press, 1969.

Jensen, G. D. Preference for bar-pressing over "frecloading" as a function of number of rewarded presses. Journal of Experimental Psychology, 1963, 65, 451-454.

Neuringer, A. J. Animals respond for food in the presence of free food. Science, 1969.166. 399

Neuringer, A. J. Many responses per food reward with free food present. Solence. 1970. 169.503. 
Singh. D. The pied piper is the protestant ethic. Psychology Today. 1972. 5. 53-56.

Skinner. B. F. Bel'ond freedom and dignity. New York: Knopf. 1971.

Stolz. S. B.. \& Lott. D. F. Establishment in rats of a persistent response producing a net loss of reinforcement. Journal of Comparative \& Physiological Psychology, 1964, 57, 147-149.

Thomas. J. Maintenance of behavior by conditioned reinforcement in the signaled absence of primary reintorcement. In D. P. Hendry (Ed.), Conditioned reinforcement. Homewood. Ill: Dorsey Press. 1969. Pp. 77-90. Thomas, J. R.. \& Hanson. C. Maintenance of fixed-interval responding by conditioned reinforcement in multiple schedules. Psychonomic Science. 1970. 19, 135-136.

Zimmerman. J.. \& Hanford. P. V. Differential effects of food frequency on behaviors maintained by concurrent schedules of primary and conditioned reinforcement. Psychonomic Science, 1967.8. 103-104.

(Received for publication July 24, 1972: revision received September 13, 1972. ) 